Hojas y Hablas No. 16, julio- diciembre de 2018. ISSN en línea 2539-3375

\title{
Infancias migrantes en Colombia: retos del derecho a la educación ${ }^{1}$ Migrant childhoods in Colombia: challenges of the right to education
}

\author{
Stephanie López Villamil ${ }^{2}$ \\ Carolina Rodríguez Lizarralde ${ }^{3}$ \\ Laura Daniela Aristizábal González ${ }^{4}$ \\ Laura Catalina Barriga Durán 5
}

\section{Resumen}

Este artículo presenta los discursos construidos a partir de la relación infancias y migraciones internacionales, mostrando cómo niñas, niños y adolescentes son vistos desde las vulnerabilidades en las migraciones y a la vez propone superar esta mirada para comprender las migraciones desde los enfoques de interseccionalidad y de derechos, centrando el análisis en el derecho a la educación en Colombia, un país que se ha convertido en lugar de tránsito y destino de migrantes, principalmente venezolanos en los últimos cinco años.

Palabras clave: Derecho a la educación; Intersectorialidad; Migración; Infancias.
Keywords: Right to education; Intersectionality; Migration; Childhoods.

\footnotetext{
${ }^{1}$ Artículo de investigación. Resultado del Proyecto Migraciones internacionales: niñez y adolescencia, desarrollado entre mayo 2017 y julio 2018 . Investigación del Grupo de investigación Migraciones y Desplazamientos, financiada por el Instituto Unidad de Investigaciones Jurídico-Sociales - Unijus de la Universidad Nacional de Colombia.

${ }^{2} \mathrm{Mg}$. en Ciencias Políticas y Sociales. Docente Universidad Nacional. https://orcid.org/0000-0002-6480-9461 E-mail: slopezv@unal.edu.co

${ }^{3} \mathrm{Mg}$. Política Social. Docente Universidad Nacional. https://orcid.org/0000-0002-4700-9374 E-mail: crodriguezl@unal.edu.co

${ }_{4}^{4}$ Especialista en Derechos Humanos y Derecho Internacional Humanitario. https://orcid.org/0000-0001-8395-1925 E-mail: ldaristizabalg@unal.edu.co

${ }^{5}$ Especialista en Derechos Humanos y Derecho Internacional Humanitario. https://orcid.org/0000-0001-8001-2017 E-mail: lcbarrigad@unal.edu.co

* Cómo citar este artículo: López, S., Rodríguez, C., Aristizábal, L., y Barriga, L. (2018). Infancias migrantes en Colombia: retos del derecho a la educación. Hojas y Hablas, (16), 10-26. DOI:10.29151/hojasyhablas.n16a1
} 


\section{Introducción}

Pensar en infancia es más bien hablar de las infancias, que al ser múltiples y diversas, permiten construir una mirada compleja de la migración. Por ello, para la investigación se propuso un enfoque de interseccionalidad, el cual contempla niñas, niños y adolescentes entre 0 y 18 años, y los diferentes cruces entre sexo, género, raza, etnia, edad, discapacidad, edades (diferenciando entre gestación, primera infancia, infancia y adolescencia). Desde las Migraciones Internacionales es preciso ubicar las condiciones económicas, las clases sociales y los procesos de empobrecimiento que generan procesos migratorios.

El término interseccionalidad es un esfuerzo por conceptualizar problemas sociales que afectan a un número de personas, dadas condiciones de discriminación o desventajas, tomando en cuenta identidades que se traslapan y experiencias que permiten comprender la complejidad de los prejuicios que estas personas enfrentan. En otras palabras, la postura teórica y metodológica de la interseccionalidad asume que existen múltiples orígenes de opresión (raza, etnia, género, sexo, orientación sexual, discapacidad, religión), los cuales crean marcas de identidad que se comunican entre sí y convergen en complejos sistemas de opresión.

Proponer la interseccionalidad como un eje de revisión dentro de los procesos migratorios permite, por un lado, develar las matrices de opresión que atraviesan a las y los migrantes, desde el nacimiento, en la infancia y la adolescencia; por el otro, visibilizar los sistemas de opresión que le otorgan ciertas características a sujetos, aumen- tando las vulnerabilidades a partir de los cruces entre las marcas de identidad. Niñas, niños y adolescentes que nacen bajo estos sistemas de opresión son categorizados por su nacionalidad, y por ello un asunto clave es asumir la interseccionalidad también para analizar el origen y el cruce entre marcas identitarias que condicionan en algunas oportunidades el acceso a derechos, o el acceso distinguido entre ciudadanos de primera, segunda o tercera categoría.

Es así como, esta investigación se propuso, en su primera fase, generar conocimiento sobre los flujos migratorios de las infancias y comprender las medidas de protección que Colombia ha establecido para la garantía del interés superior de niñas y niños. Para lograrlo, se delimitó la indagación al derecho a la educación de niñas, niños y adolescentes migrantes a partir de la búsqueda bibliográfica, de instrumentos de derecho internacional y normatividad interna, aún insuficiente para enfrentar el tema migratorio.

Por ello, y por lo poco documentado de la situación de las infancias migrantes en Colombia, este artículo pretende presentar algunos resultados de un estado del arte sobre las migraciones internacionales y las infancias, con el fin de obtener luces que permitan abrir el espacio a investigaciones posteriores. La investigación partió de la pregunta: ¿Cuáles son los contextos de goce o vulneración de derechos de las infancias migrantes en Colombia, principalmente del derecho a la educación?

De esta manera, la revisión de fuentes secundarias se enfocó en el estudio del caso colom-

${ }^{6}$ Aunque Interseccionalidad es una palabra que no se encuentra en el Diccionario de la Lengua Española' y el término ha sido una adaptación de la palabra inglesa "Intersectionality", su significado da cuenta de las interconexiones entre categorías (o categorizaciones) sociales tales como clase' raza y género aplicables a individuos o grupos' creando cruces e interdependencias entre sistemas de discriminación’ según el Diccionario de Oxford La primera vez que fue usado data del año ${ }^{1989}$ por la profesora estadounidense Kimberlé Crenshaw 
biano, teniendo en cuenta que el país se ha convertido en un país receptor de migrantes con ocasión de la actual crisis social en Venezuela, pues el país ha recibido un estimado de 1.200 .000 ciudadanos venezolanos y colombianos retornados entre los cuales han entrado y han permanecido en el territorio en situación de irregularidad y que, gracias al Decreto 1288 de 2018 y anteriores han podido obtener el Permiso Especial de Permanencia (PEP). Para ello, se utilizaron dos categorías: 1) Relación Migración y Educación, y 2) Relación Migración y Niñas, niños y adolescentes.

Las cifras oficiales calculan la llegada en 870.093 migrantes (La Republica, 2018). A partir del 6 de abril y hasta el 8 de junio del 2018, la Unidad para la Gestión del Riesgo de Desastres realizó un censo de venezolanos con la intención de tener conocimiento de esta población preguntándoles algunas cosas tales como sexo, edad, trabajo, composición familiar y profesión, entre otras (El Espectador, 2018). El 13 de junio fueron divulgados los resultados del Registro Administrativo de Migrantes Venezolanos en Colombia (RAMV) los cuales revelan 442.462 personas registradas: $49,67 \%$ mujeres, $50,24 \%$ hombres y 0,075 trans; $y$ 253.575 familias de estas 118.709 son niños niñas y adolescentes de los cuales 33.107 están estudiando actualmente (Unidad Nacional para la Gestión del Riesgo de Desastres, 2018). En el RAMV, se registraron 58.667 niñas y 60.038 niños siendo los de 0 a 5 años los más numerosos con 50.729 registros, lo cual plantea un desafío mayor para el gobierno en términos de la atención a estos niños y su posterior integración en la sociedad colombiana.

El texto presenta en un primer momento la metodología empleada para agrupar la información secundaria revisada; en segundo momento, una reflexión para analizar los resultados desde la interseccionalidad y la vulnerabilidad en las mi- graciones. Finalmente, se hace una discusión a la luz de la normatividad vigente en Colombia frente al derecho a la educación de niñas, niños y adolescentes migrantes, que permiten concluir cuáles son los contextos de vulneración y goce del derecho elegido.

\section{Metología}

El presente es un estudio exploratorio de la relación migraciones internacionales e infancias en el marco del derecho a la educación, centrado en el caso colombiano a partir de la construcción de un estado de la cuestión, que recopiló y sistematizó la información obtenida de diferentes fuentes secundarias, y del marco normativo y jurisprudencial existente, del cual se desprende un análisis textual. Toda la información se sistematizó en una base de datos disponible en la nube y se clasificó de la siguiente manera:

Relación Migración y Educación

- Instrumentos de derecho internacional y regional

- Derecho a la educación por países (requisitos para vinculación a los sistemas educativos colombiano y chileno)

Relación Migración y Niñas, niños y adolescentes

- Cuidado de NNA o el lugar de los adultos cuidadores migrantes (mercado de trabajo, tiempos establecidos hogar / trabajo o cualquier institución que atienda su cuidado) - Tipologías de migración (reunificación familiar, nacimiento, adopción, entre otras)

- Diferencias de migración por edades: 0-5; 6-11; 12-17 años.

- Experiencias de niñez en Colombia

- Experiencias de niñez por etnia y raza

- Experiencias de niñez por sexo

- Experiencias de niñez por discapacidad

Para la etapa de organización, se diseñó una 
matriz que permitiera clasificar los datos previamente recolectados. El resultado fue una tabla compuesta por 8 columnas y n filas. La extensión de estas últimas se determinó por el número de textos seleccionados. En cuanto a las columnas, se utilizaron las siguientes variables numéricas y categóricas: Título, Autor, Fecha, Tipo de documento, Enlace, Observaciones, Categoría y Categoría 2 (opcional).

Las columnas que llevan por título "Categoría" y "Categoría 2 (opcional)" tuvieron como propósito clasificar por temática el contenido de los documentos objeto de estudio. En este ejercicio se utilizaron los siguientes conceptos:

1. Cuidado de NNA o el lugar de los adultos cuidadores migrantes. Se refiere a los documentos que indagan en las labores del cuidado desempeñadas por los adultos migrantes y en las dinámicas del cuidado de NNA derivadas de los fenómenos migratorios.

2. Derecho a la educación por países. Aplicable toda vez que se haga referencia a los requisitos para vinculación al sistema educativo colombiano.

3. Diferencias de migración por edades. Para esta categoría se tuvo cuenta si se hablaba acerca de NNA atendiendo a estos intervalos de edad 0-5, 6-11 y 12-17.

Experiencias de niñez por países. Fue utilizada para describir aquellos textos que exploran el fenómeno migratorio de NNA en distintos contextos nacionales.

4. Experiencias de niñez por etnia y raza. Clasificó los documentos que se centraran en el tema étnico y racial en NNA.

5. Experiencias de niñez por sexo. Describe los abordajes con enfoque de género para NNA migrantes.
6. Experiencias de niñez por discapacidad. Análisis empíricos que tratan el tema de discapacidad.

7. Instrumentos de derecho internacional y regional. Se circunscribieron en esta categoría los textos que dieran cuenta de la normatividad producida en el marco del sistema de derechos humanos universal, así como en las organizaciones y organismos regionales.

8. Tipologías de migración. Son las razones que subyacen a la migración de NNA.

9. Políticas públicas migratorias por países. Se aplicó a los textos que describen planes, programas y/o proyectos realizados o por hacerse en distintos Estados.

Cada uno de los textos fue incluido de acuerdo a los anteriores conceptos. En algunos casos los textos podían clasificarse en más de una categoría. Por esta razón se optó por establecer otra columna (Categoría 2) a fin de adicionar alguna categoría pertinente para el análisis.

El total de textos revisados fue 50, de los cuales se incluyeron a la matriz 35 , tales como libros, capítulos de libros y artículos sobre la materia, normas y jurisprudencia nacional e internacional sobre la materia en los últimos 17 años (2000-2017), e informes de derechos humanos de infancia y adolescencia migrante de los organismos internacionales, distribuidos de la siguiente manera: 


\begin{tabular}{ll}
\hline \multicolumn{2}{c}{ NÚMERO DE TEXTOS POR CATEGORÍA } \\
\multicolumn{1}{c}{ Categoría } & Número de textos \\
Cuidado de NNA o el lugar de los adultos cuidadores migrantes & 2 \\
Derecho a la educación por países & 2 \\
Diferencias de migración por edades & 2 \\
Experiencias de niñez por etnia y raza & 3 \\
Experiencias de niñez por sexo & 0 \\
Experiencias de niñez por discapacidad & 0 \\
Instrumentos de derecho internacional y regional & 9 \\
Tipologías de migración & 9 \\
Políticas públicas migratorias por países & 8 \\
\hline
\end{tabular}

\section{Resultados y discusión}

Como se ha dicho, infancia se asume como la categoría que identifica socioculturalmente a un grupo de personas de acuerdo con sus edades; mientras niñas y niños son las personas que integran dicho grupo social denominado como fenómeno infancia. Entonces, infancia no es una categoría homogénea; por el contrario, cuando hablamos de infancia es preciso pensar en diversidad, pluralidad, desigualdad, multiplicidad y disparidad. Así, es pertinente hablar de infancias, comprendiendo las experiencias variadas de niñas, niños y adolescentes (NNA), dentro del grupo reconocido como "menores de 18 años".

El propósito de este apartado es, en primer lugar, presentar una propuesta de cómo abordar la diversidad de infancias, así como las vulnerabilidades asociadas a las migraciones de niñas, niños $y$ adolescentes, $y$ en segundo lugar, hacer un aterrizaje en el caso colombiano frente a la garantía del derecho a la educación, a partir de la revisión de fuentes secundarias realizada.

\section{Infancias migrantes}

Como derechos de NNA se establecen los principios de existencia, desarrollo, ciudadanía y protección. El derecho a la educación es tomado como un derecho fundamental para el desarrollo y el ejercicio ciudadano, interpelando a los Estados a promover, proteger y garantizar la educación de toda persona menor de 18 años. El interés superior del niño como principio de los diferentes instrumentos de derecho internacional, así como de las normatividades nacionales, pone presente la responsabilidad de la protección integral, es decir, de todos los derechos en conjunto y el restablecimiento inmediato en caso de vulneración o violación. Bajo un ejercicio de ponderación, siempre la decisión deberá favorecer a niñas, niños y adolescentes.

De otro lado, no es posible unificar experiencias en la categoría "migrante", al desconocer las particularidades de quienes cruzan las fronteras internacionales. No obstante, el consenso existente defiende que cuando se habla de migraciones internacionales de niñas, niños y adolescentes se consideran tres vías de migración: 1) NNA migran junto a sus familias; 2) se presenta únicamente migración parental, quedando NNA a cargo de otro familiar; y 3) migración de NNA no acompañados o separados fuera de su país de origen.

Niñas, niños y adolescentes migrantes deben ser contemplados como sujetos de derechos y de investigación, recogiendo sus voces frente a los factores para la migración y sus experiencias durante los flujos de manera regular e irregular, las condiciones que se viven en los países de origen, tránsito y destino.

NNA migran solos o con sus familias, dentro del territorio nacional o atravesando fronteras internacionales, en busca de trabajo o educación, para mejorar su situación personal o para explorar el mundo y en algunos casos por reunificación familiar. Es 
así como los menores de edad constituyen una gran proporción de los flujos migratorios, sobre todo, en la migración a los países en desarrollo (Organización Internacional del Trabajo, 2013, p. 15).

Y los últimos acontecimientos en Estados Unidos con niñas, niños y adolescentes migrantes que fueron separados de sus familias nos recuerda que:

Los niños no deben ser privados de la libertad, salvo como medida de último recurso, y ello debe hacerse por el periodo de tiempo apropiado más breve posible, teniendo en cuenta como consideración principal el interés superior del niño para la determinar la duración y las condiciones de la privación de libertad y teniendo igualmente en cuenta la extrema vulnerabilidad de menores no acompañados y su necesidad de atención (Mercosur, 2016, p. 16).

Así mismo, que la devolución a su país de origen solo se puede hacer si prima el interés superior. Entonces, se hace necesaria una revisión crítica de los documentos producidos frente a la relación migraciones internacionales e infancias, siguiendo el llamado que hace la UNICEF (2017) frente a la necesidad urgente de incluir el punto de vista de la infancia y la adolescencia en las políticas migratorias.

Se resalta que la no devolución de NNA es un principio donde los Estados deben evaluar no solo si la vida o la integridad física del niño o niña corren peligro, sino en un sentido más amplio que implica si sus condiciones mínimas para su desarrollo integral están amenazadas, tales como alimentación, vestuario, salud o educación (Mercosur, 2016).
El reconocimiento del interés superior de niñas, niños y adolescentes implica conversar y no solo decidir cómo personas adultas sobre lo que se considera es su bienestar, porque precisamente puede ser un despropósito establecer medidas que terminan perjudicando a quienes migran por distintas causas, y además no son contemplados en entrevistas con funcionarios de migración, personal psicosocial e investigadores sociales.

Las razones de migración son voluntarias o forzadas, y las necesidades de acuerdo a las edades suponen una diversidad de experiencias. A continuación, se intentará relacionar cada ciclo vital de las y los menores de 18 años, con las migraciones.

La educación es un mecanismo de integración de niñas, niños y adolescentes migrantes, siendo un aspecto clave a evaluar la inserción de ellas y ellos en la escuela, demandando a la propia escuela una política intercultural.

\section{Gestación y nacimiento}

La migración de mujeres embarazadas, así como los partos en los países de destino o de tránsito durante la migración remiten al derecho a la nacionalidad y al derecho a tener un nombre, ante lo cual se solicita el reconocimiento jurídico por parte del Estado como ciudadano nacional. Puede suceder que un niño o niña sea considerado apátrida, si no se da el reconocimiento, limitando el acceso a servicios sociales.

\section{Primera infancia}

Se consideran que los primeros años de vida son las bases del desarrollo infantil. Las estrategias dirigidas a niñas y niños entre los 0 y 5 años de edad son reconocidas internacionalmente como la mejor inversión de los Estados. Durante esta fase se inicia el paso de la socialización primaria (al in- 
terior de la familia) a la secundaria, en la que se inicia la asistencia a jardines o el cuidado de personas externas a la familia.

El derecho a la educación puede remitirse al acceso a la oferta de jardines o programas del cuidado de niñas y niños al interior de sitios de trabajo, por medio de la didáctica, el juego y los hábitos de higiene, alimentación y procesos comunicativos.

\section{Infancia}

La educación primaria está contemplada en el ciclo vital de la infancia (6 a 11 años), y es obligación de los Estados garantizar el acceso gratuito y la permanencia de todos los menores en el sistema educativo, sin distinción alguna, incluso para menores extranjeros. Se reconocen el derecho a la alimentación y el libre desarrollo de la personalidad como derechos conexos a la asistencia de niñas y niños a las instituciones educativas.

En estos contextos también se empieza a experimentar la discriminación, el racismo y la xenofobia, por lo que situaciones de bullying o acoso escolar pueden ser recurrentes, haciendo necesario que las personas adultas estén alertas y al cuidado de quienes pueden ser víctimas de estas situaciones.

\section{Adolescencia}

La adolescencia está asociada a la educación secundaria, y en algunos países varía el número de grados académicos por cursar; así como también puede variar el paso de la adolescencia a la edad adulta. Sin embargo, existe consenso frente a la mayoría de edad a los 18 años en gran parte de países. Igualmente, la edad en la que un menor de edad puede trabajar, con permiso de sus padres, internacionalmente se reconoce a los 15 años, por tanto, hay motivaciones para generar ingresos en menores de edad adolescentes principalmente, así como un desarrollo autónomo de actividades. Frente a las migraciones, es en esta etapa de la vida se aumentan las posibilidades de migrar no acompañados, así como las motivaciones laborales.

La condición de minoría de edad, en todas las etapas de lo que se denominaron anteriormente como infancias, conlleva a que la responsabilidad sobre niñas, niños y adolescentes sea soportada por los actores: familia, comunidad y Estado. Dichos actores se organizan en etapas de socialización primaria y secundaria, así como gestionan diferentes acciones para el cuidado, la protección y la garantía de derechos.

\section{Familias}

La familia como categoría social y analítica permite pensar en las diversas formas de conformación familiar existentes y cómo éstas están asociadas a los flujos migratorios. Hoy se habla incluso de familias transnacionales, problematizando aquella idea de la necesidad de compartir un mismo techo (hogar).

La familia como institución ha sido la encargada de velar por la socialización primaria y la protección de niñas y niños al interior de su grupo, así como de proveerles las condiciones dignas para su desarrollo integral, entre estas la permanencia en un sistema educativo. Cuando la familia está en movilidad, algunas de estas garantías no se pueden suplir al interior de la red, por la que

\footnotetext{
${ }^{7}$ Según lo establecido en el artículo 96 de la Constitución Política de Colombia, se consideran nacionales colombianos por nacimiento "que, siendo hijos de extranjeros, alguno de sus padres estuviere domiciliado en la República en el momento del nacimiento". Esto plantea el riesgo de apátrida pues, muchos de estos inmigrantes se encuentran en situación irregular en Colombia, sin la posibilidad de domiciliarse, con lo cual, sus hijos no podrían tener acceso a la nacionalidad.
} 
las comunidades o el Estado terminan asumiendo ciertas responsabilidades. Incluso se afirma que las migraciones significan una crisis para las familias que la viven, tanto para quien migra, como para quienes se quedan.

\section{Comunidades}

Es preciso ubicar la discusión en las comunidades receptoras de familias, niñas, niños y adolescentes en los países de tránsito y destino, así como de las comunidades que asumen el cuidado de quienes son devueltos a sus países de origen.

Al interior de las comunidades, el cuidado y la protección de niñas, niños y adolescentes es directamente equivalente a las creencias y las prácticas socioculturales del territorio. Así que esta puede llevar a conflictos, teniendo en cuenta las variables de género, etnicidad y racialización. Así mismo, las comunidades ejercen "sanción social" frente a lo que se considera es socialmente aceptado con sus menores.

NNA migrantes pueden no ser considerados "sus" menores, o siquiera ser un asunto de protección, generando categorización de ciudadanías y la posibilidad de ejercicio de las mismas. Obviamente, el acceso a la educación ingresa en este debate frente al acceso y la convivencia con otras niñas, niños y adultos que quizás no les consideran sujetos de protección.

\section{Estados}

La crianza de niñas y niños es una labor que recae en las familias, y en algunos casos en comunidades barriales, organizaciones sociales o instituciones educativas. Al Estado le corresponde promover y garantizar los derechos, principalmente el de protección de NNA, y se supone que su actuación viene dada por el incumplimiento de los actores familia y comunidad.

No obstante, en sus obligaciones de respeto y garantía de los derechos humanos, la promoción de la educación es un asunto primordial en poblaciones de especial protección como son niñas, niños y adolescentes, sin distinción alguna, y allí se reconoce a las infancias migrantes.

Es importante resaltar que los intereses de los Estados, asociados a la regulación de las migraciones, están por debajo del interés superior de niñas, niños y adolescentes. Por tanto, ningún Estado puede argumentar la desprotección por acción u omisión de menores de 18 años, argumentando intereses como soberanía nacional, falta de capacidad instalada u otras.

Empero, la mayoría de Estados suelen anteponer sus intereses de seguridad nacional en las agendas migratorias, y no un enfoque de derechos humanos, violando el principio de interés superior del niño. Por tanto, la lectura de fuentes secundarias que sigue a continuación, busca observar cómo se comprenden las infancias en las migraciones desde la interseccionalidad.

\section{Relación migraciones internacionales e in- fancias vistas desde las vulnerabilidades}

Una de las problemáticas con las que se encuentran los NNA migrantes es la vulnerabilidad ante múltiples situaciones en las que pueden verse involucrados en el proceso migratorio. Estas vulnerabilidades han sido rescatadas en varios textos. Es importante destacar que, en general, en América Latina,

el niño se ve enfrentado a un mundo que altera severamente las posibilidades de desarrollo de todas sus potencialidades, y lo expone a situaciones que llegan a dañarlo gravemente. Estas situaciones son el abandono familiar, la explotación laboral o sexual, su alejamiento de las instituciones edu- 
cativas o involucrarse con grupos de riesgo que lo empujen en una espiral de daños cada vez mayores (Petit, 2003, p. 17)

En su proceso, los NNA se enfrentan a unos riesgos que aumentan en el caso de que su migración se efectúe de manera forzosa como es el caso de los venezolanos y retornados colombianos. El tema de la explotación laboral es de especial preocupación para la UNICEF: desde una aproximación teórica de los factores de expulsión y atracción (push-pull) de las migraciones internacionales, se estudia la migración infantil siendo uno de los principales factores de expulsión la pobreza, y de atracción la búsqueda de empleos mejor remunerados (Edmonds y Shrestha, 2009). Esta visión enfatiza en el economicismo de las migraciones y deja de lado el carácter más humano de las migraciones relacionado con los riesgos de estos NNA afectados en su vulnerabilidad por la explotación laboral. El texto enfatiza en los vacíos en el estudio de la migración laboral de NNA a nivel de las estadísticas y argumenta que es necesaria para una formulación de política pública efectiva. -En otro texto se hace referencia a la necesidad de estudios cualitativos sobre menores no acompañados o independientes o autónomos- (Aitken, 2009).

En la misma línea, desde la OIT se abarca el tema del tráfico de migrantes y de la explotación laboral infantil y enfatiza en la protección de los menores (Van de Glind, 2010a). Se señalan entre muchas vulnerabilidades de los NNA que "Children who migrate without their parents are especially vulnerable to exploitation, coercion, deception, and violence - particularly if they are below the minimum age of employment, cross a border illegally and do not speak the language of their destination" (Van de Glind, 2010b, p. 9).
En ambos casos se resalta la diferencia de la migración laboral a lo que se categoriza como migración "independiente" de los NNA lo cual genera más riesgos y más vulnerabilidad ante situaciones de explotación laboral. Siguiendo con los riesgos de los menores no acompañados por sus padres en el proceso migratorio, se hace un estudio en tres países, incluido Chile, que se resalta la necesidad de diferenciar la migración infantil dada la vulnerabilidad de esta población y, desde una perspectiva de migración y desarrollo también llama la atención sobre la falta de información cuantitativa al respecto (Yaqub, 2009).

Aquí, es importante tener en cuenta que, "aunque la migración de niños, niñas y adolescentes implica altos riesgos de explotación laboral y de trata infantil, la percepción que se pueda tener de este fenómeno en los países desarrollados difiere sensiblemente de su aprehensión en los países en desarrollo" (Khoudour-Castéras, 2009, p. 231); este autor retoma sobre el tema educativo un aspecto fundamental para la comprensión del acceso a la educación de los NNA migrantes, esto es, el factor pobreza. Así, entre más necesitada está la familia en términos financieros es mayor la probabilidad de que el niño o la niña empiecen a trabajar en detrimento de sus estudios y, al contrario, el acceso a la educación retrasa la edad en que se inserta al mercado laboral. Se resalta la vulnerabilidad de las poblaciones indígenas en particular en las migraciones transfronterizas; en cuanto a las migraciones internacionales se destaca la migración de jóvenes con un riesgo adicional y es el de caer en redes de trata o explotación sexual comercial, además de la posibilidad de insertarse en la criminalidad.

Otra vulnerabilidad latente entre los NNA migrantes es la explotación sexual. Esto es analizado en el contexto chileno (Pavez-Soto, 2016) a 
partir de un estudio cualitativo que concluye sobre la necesidad de empoderar a las niñas migrantes, pues los contextos de discriminación y sociedades paternalistas impiden esto. Una problemática con la que se encuentran los NNA migrantes es justamente el de la discriminación que es un problema mayor en la escuela. Un estudio analiza los niños y niñas migrantes peruanos en Chile desde el transnacionalismo subrayando la necesidad de descolonizar el pensamiento sobre los estudios de la niñez migrante (Suárez-Cabrera, 2015) que siguen reproduciendo la estructura racista hacia la migración sur-sur. Este aspecto suma en términos de las vulnerabilidades a las que son expuestos los NNA.

En conclusión, gran parte de los estudios sobre infancias migrantes en Colombia están centrados en la explotación laboral, desde una perspectiva economicista de las migraciones internacionales. Por tal razón, se hacen necesarias investigaciones que den cuenta de aspectos de la integración de niñas, niños y adolescentes a comunidades de acogida e instituciones educativas; por ejemplo, desde una perspectiva psicosocial, se resalta el estudio de múltiples violencias asociadas al racismo, la xenofobia y el acoso escolar, así como otras formas de explicar los procesos migratorios de NNA frente al acceso a la educación, generando recomendaciones frente a los riesgos existentes por medio de políticas públicas de prevención.

\section{Enfoque de derechos, interseccionalidad y derecho a la educación}

La Constitución Política de Colombia (1991) establece en el artículo 67 la educación como un derecho y un servicio público que cumple una función social, mencionando de igual forma que

El Estado, la sociedad y la familia son res- ponsables de la educación, que será obligatoria entre los cinco y los quince años de edad y que comprenderá como mínimo, un año de preescolar y nueve de educación básica. La educación será gratuita en las instituciones del Estado, sin perjuicio del cobro de derechos académicos a quienes puedan sufragarlos.

Así mismo, el artículo 44 que trata sobre los derechos y protecciones especiales de que gozan niños y niñas, establece la educación como un derecho fundamental.

Lo anterior, se debe interpretar de forma complementaria con los tratados internacionales existentes sobre la materia ratificados por Colombia y que de acuerdo al artículo 93 de la Constitución Política (1991) hacen parte del Bloque de Constitucionalidad. La ley general de educación en Colombia expedida el 8 de febrero de 1994 (Ley No. 115, 1994), determina las normas generales para la prestación del servicio público de educación incluyendo el enfoque diferencial para grupos étnicos y para personas en situación de discapacidad (La ley No. 1618, 2013 establece las disposiciones para garantizar el pleno ejercicio de los derechos de las personas con discapacidad, y en particular en el artículo 11 establece el derecho a la educación a través del fomento, su acceso y permanencia bajo una perspectiva de inclusión).

En desarrollo del mandato constitucional señalado en los artículos mencionados, el 8 de noviembre de 2006 se expidió el Código de la Infancia y la Adolescencia (Ley No. 1098, 2006), el cual tiene como propósito principal garantizar el pleno desarrollo de niñas y niños y sus derechos, primando siempre el derecho a la igualdad y dignidad humana sin que pueda existir discriminación alguna. Resulta relevante mencionar que de acuerdo a lo establecido en la ley son titulares de 
derechos todas las personas menores de 18 años que sean nacionales, así como los extranjeros que se encuentren en territorio nacional. El Código indica que en toda actuación tanto judicial como administrativa o de cualquier naturaleza que tenga relación con un menor, prevalecerán sus derechos y se deberá tener en cuenta el principio del interés superior del menor (Sentencia T-260/12), es decir, la obligación del Estado de brindar protección especial a los derechos de niñas, niños y adolescentes.

Acerca de los requisitos que las instituciones educativas deben solicitar a los estudiantes, se encuentran la comprobación de la inscripción en el registro civil de nacimiento y que el menor se encuentre afiliado a un régimen de salud.

El Decreto Único Reglamentario del Sector Educación (Decreto Único Reglamentario No. 1075 de 2015), en su artículo 2.3.3.1.2.3, indica que

Todos los residentes en el país sin discriminación alguna, recibirán como mínimo un año de educación preescolar y nueve años de educación básica que se podrán cursar directamente en establecimientos educativos de carácter estatal, privado, comunitario, cooperativo solidario o sin ánimo de lucro.

Y establece los niveles, ciclos y grados en los que la educación básica formal se organiza.

Mediante el Decreto 4807 del 20 de diciembre de 2011(Decreto No 4807, 2011), compilado en el citado Decreto Único Reglamentario del Sector Educación (Decreto Único Reglamentario No. 1075 de 2015), el Ministerio de Educación Nacional estableció las condiciones de aplicación de la gratuidad educativa respecto al pago de derechos académicos y servicios complementarios para los niveles de educación preescolar, primaria, secundaria y media en centros educativos públicos, incluyéndose hasta el undécimo grado.

En el año 2016 se estableció la política para el desarrollo integral de la primera infancia "De Cero a Siempre" (Ley No. 1804, 2016), con la cual se busca "el reconocimiento, la protección y la garantía de los derechos de las mujeres gestantes y de los niños y las niñas de cero a seis años de edad, así como la materialización del Estado Social de Derecho". En el artículo 5 se indica que la educación inicial es un derecho de los menores de 6 años, con lo cual se complementa y amplía la cobertura educativa existente.

En la actualidad la Secretaría de Educación de cada lugar, de conformidad con la ley, establece los requisitos mínimos para proceder a matricular a los menores, no solo venezolanos sino en general; así se tiene a manera de ejemplo que en la ciudad de Cúcuta solicitan fotocopia del documento de identificación del aspirante, fotocopia de un recibo de servicio público y el formulario de inscripción; en Bogotá los requisitos son el documento de identidad del estudiante y del acudiente, un recibo de servicio público de la vivienda y datos de contacto; en Medellín solo solicitan para la inscripción el documento de identificación; en Barranquilla demás del documento de identificación piden los certificados de estudios y aprobación de años anteriores.

Acceso de niños, niñas y adolescentes migrantes al sistema educativo en Colombia

Los menores extranjeros que se encuentren en el país son titulares de los mismos derechos y protecciones que los nacionales colombianos. No obstante, y realizando una interpretación conjunta 
con la normatividad migratoria vigente en el país (Decreto No. 1067, 2015), el artículo 2.2.1.11.5.2. determina que, para las actividades académicas los establecimientos educativos deberán exigir a los estudiantes extranjeros de cursos regulares la visa que los faculte para realizar sus estudios antes de la iniciación de clases e informar por escrito o por los medios electrónicos establecidos para tal fin a la Unidad Administrativa Especial Migración Colombia, de la matrícula de estudiantes extranjeros y de la terminación definitiva de sus estudios dentro de los treinta (30) días calendario siguientes a la ocurrencia de los mismos.

Dicho requisito representa en la práctica un obstáculo en aquellos casos en los que los menores y sus familias debieron ingresar al país de forma irregular y no les es posible contar con el visado correspondiente. Por ejemplo, desde Venezuela se ingresa a Colombia por puntos fronterizos no autorizados sin regularizar la situación en el país, impidiendo prima facie que los menores puedan acceder a la educación gratuita suministrada por el Estado. Sin embargo, y ante esta problemática, el Ministerio de Educación expidió las Circulares No. 45 de septiembre de 2015 (Circular No. 45, 2015), No. 7 de febrero de 2016 (Circular No. 7, 2016), y la No. 1 de 2017 (Circular No. 1, 2017) con el objetivo de garantizar el derecho a la educación de la población en edad escolar, proveniente de Venezuela, sin desconocer el cumplimiento de los deberes en cuanto al reporte a Migración Colombia que deben realizar las instituciones educativas. Así, se garantiza que todos los menores, incluyendo a aquellos que están en situación mi- gratoria irregular puedan acceder a la educación por tratarse de un derecho fundamental. Jurisprudencia colombiana respecto al acceso a la educación de niños y niñas migrantes

La Corte Constitucional (Sentencia T-660, 2013) estudió el caso de un menor de 15 años cuyo acceso a la educación estaba siendo negado por cuanto no contaba con visa que le permitiera estudiar en el país y tampoco había concluido su proceso de nacionalización por ser hijo de padres colombianos. La directora de la institución educativa argumentó que, si bien había ya realizado varios grados en el colegio, no le era posible continuar con el proceso de matrícula para el grado décimo, por tanto, Migración Colombia los sanciona por recibir a un estudiante que no tenía la documentación pertinente que lo habilita para estudiar. Al estudiar el caso, la Corte reiteró que jurisprudencialmente se ha reconocido el carácter fundamental del derecho a la educación particularmente para NNA, lo anterior en armonía con los instrumentos ratificados por Colombia (Pacto Internacional de Derechos Económicos, Sociales y Culturales, 1966), (Protocolo de San Salvador, 1988) y (Convención de los Derechos del Niño, 1989) y en consecuencia resulta viable como mecanismo de protección el uso de la acción de tutela para aquellos casos en los que se considera violado el derecho.

Así mismo, respecto a las obligaciones en cabeza del Estado y como principal responsable de prestar el servicio, de acuerdo a la Corte Constitucional (Sentencia T-308, 2011), se estableció respecto al derecho a la educación que esta exige del Estado el cumplimiento de tres tipos de obliga-

${ }^{8}$ De forma complementaria, la Constitución Política de Colombia, también establece en su artículo 100 que "los extranjeros disfrutarán en Colombia de los mismos derechos civiles que se conceden a los colombianos. (...) y gozarán de las mismas garantías concedidas a los nacionales, salvo las limitaciones establecidas por la Constitución y la ley (...)", el cual se acompasa con el derecho fundamental a la igualdad consagrado en el artículo 13. 
ciones: de respetar, proteger y cumplir. La primera demanda de los Estados es la evasión de circunstancias que obstaculicen o impidan el disfrute del derecho a la educación; la de protección les impone la obligación de adoptar medidas que impidan su obstaculización por parte de terceros; y la de cumplimiento, que comprende las obligaciones de facilitar y proveer, exige de los Estados la adopción de medidas positivas que permitan a individuos $y$ comunidades disfrutar del derecho a la educación, en la mayoría de los casos, mediante la provisión directa del servicio o la autorización de particulares para el efecto.

Correlativamente, por la función social que cumple el servicio de educación, también se han establecido ciertos deberes y exigencias que tienen que cumplir la familia y sociedad, debiendo cumplir los padres con las cargas mínimas establecidas en la ley para que los niños, niñas y adolescentes accedan y permanezcan en el sistema educativo, dentro de los que se incluyen los trámites para regularizar la escolaridad de los menores.

La Corte decidió tutelar el derecho fundamental a la educación del menor teniendo en cuenta que la falta del cumplimiento de la permanencia regular en el país no puede ser obstáculo para que el menor continúe estudiando y más cuando ya lo venía haciendo desde hace 4 años. La Corte recuerda que no es una carga desproporcionada el cumplimiento de los requisitos mínimos establecidos en la ley para el acceso a la educación de menores extranjeros y deja de presente que estos requisitos en ningún caso se pueden constituir en un impedimento para el goce efectivo del derecho desde los cuatro aspectos estructurales que lo componen.

En la Sentencia T-250, 2017 la Corte entró a revisar la situación de una familia venezolana que, ante la negativa del Ministerio de Relaciones Exteriores de concederles el estatus de refugiados, interpusieron acción de tutela contra la decisión proferida. Dentro del trámite del proceso de revisión, si bien los accionantes contaban con medidas transitorias entre las cuales se encontraban los salvoconductos por los cuales podían permanecer de manera temporal en Colombia ellos y sus hijas, este documento no les permitía a sus hijas acceder al sistema de educación porque éste no era suficiente para matricularlas, pese que en un primer momento a su hija menor la habían admitido en un Centro de Desarrollo Integral pero que para el siguiente año le negaron el cupo por no encontrarse afiliada a ninguna Entidad Prestadora de Salud.

Ante esta situación, la Corte Constitucional solicitó información al Ministerio de Educación con el fin de establecer los requisitos y conocer la forma en la que se presta el servicio de educación a extranjeros, con el fin de determinar si existió una vulneración al derecho a la educación. La Corte luego de estudiar la información entregada, confirmó que el acceso a educación gratuita cobija tanto a nacionales como extranjeros en igualdad de condiciones y que no obstante, los extranjeros sí deben cumplir con algunos requisitos adicionales para su ejercicio como lo es el trámite correspondiente de visa, situación que debe ser verificada por la institución educativa y reportada a Migración Colombia en los términos establecidos en la ley, so pena de incurrir en sanción por la falta de cumplimiento de este requisito. Dicho requisito adicional solicitado a los extranjeros para la Corte resulta razonable por cuanto permite los fines de la política migratoria fijada por el Estado y por otro lado permite la identificación de la persona que está cursando los estudios y la certificación por parte de la institución de los estudios realizados. 


\section{Conclusiones}

En Colombia los obstáculos que existen en la práctica, afectan la garantía del derecho a la educación para migrantes, pues aunque se han tratado de erradicar mediante medidas transitorias que permitan salvaguardar los derechos de los niños, niñas y adolescentes entendiendo las dinámicas actuales y los retos que las nuevas dinámicas migratorias, estas resultan insuficientes para garantizar de manera sostenible y consistente el interés superior de niñas y niños, pues continúa primando el interés de los Estados.

No obstante, la legislación colombiana muestra avances hacia la protección integral de los niños, niñas y adolescentes, incluyendo a los migrantes, siguen persistiendo grandes retos en materia de política pública y normatividad más flexible que dé cuenta y comprenda la realidad migratoria y los flujos migratorios, con el fin de garantizar de forma efectiva los derechos fundamentales establecidos en el ordenamiento de cada país. En materia de educación, se resalta la adopción por parte del máximo órgano constitucional de Colombia de la doctrina internacional sobre la comprensión y alcance del derecho a la educación de las cuatro dimensiones básicas que se relacionan entre sí, y que en últimas buscan materializar el acceso de los niños y niñas a la educación en condiciones dignas y respetando el interés superior de éstos.

El interés superior de niñas, niños y adolescentes prima sobre los intereses de la política migratoria de cualquier Estado. Así, la migración de NNA concierne a los países de origen, tránsito y destino. NNA migrantes irregulares tienen un acceso complicado al derecho a la educación por obstáculos de distinto tipo, y las condiciones de vida precarias que viven tienen incidencia directa en su proceso educativo (Ortega, 2014).
El derecho a la educación contempla tres facetas: 1) el derecho a acceder y permanecer en la escuela; 2) el derecho a aprender (calidad); y 3 ) el derecho a no discriminación y a buen trato en el ámbito de la educación (Contreras, Cortés y Fabio, 2012). Así, se recomienda revisar cuidadosamente los procesos asimilación o de integración de las infancias migrantes a través de la escolarización, pues ésta funciona como un indicador del grado de integración.

El desconocimiento de los alcances, limitaciones y exigibilidad de los derechos humanos por parte de las poblaciones lleva a nuevas violaciones de sus derechos, y los sujetos más afectados son las familias migrantes y sus NNA.

Desde la matriz de interseccionalidad también es necesario pensar y analizar las migraciones internacionales en niñas, niños y adolescentes. Por un lado, se observa que no hay especificidades frente a las necesidades de cada ciclo vital de lo que se denomina "infancia”, así como es difícil contemplar dichas distinciones en los sistemas educativos. Por ejemplo, en el estado del arte exploratorio no se encontraron estudios que hablen del cuidado de menores en jardines, y los estudios cualitativos se concentran en edades desde los 6 años en adelante. Las personas de 15 años en adelante ya son consideradas jóvenes y suelen pocas veces comprenderse dentro de la categoría adolescente.

Si bien hay un avance interesante en la inclusión del análisis de género en algunos trabajos, éste enfoque debe ser transversal a cualquier intento por explicar dinámicas de las infancias migrantes, así como debe serlo un enfoque étnicoracial para explicar las diferentes violencias que enfrentan los NNA. También urge conectar orientaciones sexuales en menores de edad a los estu- 
dios sobre riesgos y vulnerabilidades frente a la trata de personas y la explotación sexual, al igual que miradas sobre la discapacidad en explotación laboral, sexual, mendicidad y utilización para la comisión de delitos.

En efecto, entre los numerosos riesgos a los que son expuestos los NNA en los procesos migratorios se encuentran la explotación laboral y la explotación sexual analizados en mayor medida desde lo cuantitativo. Sin embargo, hace falta un análisis de las vulnerabilidades en otros aspectos como su alejamiento de las instituciones educativas desde un enfoque interseccional, pero apoyado también en la formulación de políticas preventivas ante este riesgo.

En materia de investigación académica, los estudios sobre migraciones deberán proponer una revisión del goce efectivo de derechos de niñas, niños y adolescentes migrantes, reconociendo además los procesos de integración en los escenarios escolares y comunitarios. Es momento de pensar el cuidado de menores no escolarizados, así como de conectar las experiencias en salud de mujeres gestantes, así como el reconocimiento de ciudadanía jurídica (patria) a recién nacidos y atención en jardines infantiles u hogares del Instituto Colombiano de Bienestar Familiar - ICBF.

Desde las vulnerabilidades se hace necesario considerar miradas diferenciales sobre etnia, edad, sexo, género, discapacidad y orientación sexual, un tema que se ha obviado en menores de edad y que se relaciona con explotación sexual y comercial de NNA, así como la utilización de menores en la comisión de delitos, tales como la pornografía, el microtráfico y la vinculación a grupos criminales en Colombia.

Sobre todo, futuras investigaciones requie- ren superar la perspectiva adultocéntrica que asume niñas y niños como sujetos pasivos, para darles voz y permitirles reflexionar y encontrar salidas a sus problemas. La pedagogía de la acción y la investigación participativa implica darles el lugar que merecen como sujetos de derechos activos, empleando metodologías que pongan en diálogo a investigadores con niñas y niños; incluso que sean NNA investigadores de sus propias realidades, conformando semilleros desde las escuelas, que promuevan la integración real y efectiva, sin racismo, xenofobia y ningún tipo de discriminación. Un gran desafío como país receptor de migrantes y comprometido con las nuevas generaciones.

\section{Referencias}

Constitución Política de Colombia. (1991).

Contreras, D., Cortés, S. \& Fabio, C. (2012). Niños, niñas y adolescentes y su derecho a la educación en Chile. En: C. Silva Gallinato (Ed.). Los derechos de los niños, niñas y adolescentes migrantes, refugiados y víctimas de trata internacional en Chile. Avances y desafíos, 217-242. Recuperado de http://www. unicef.cl/web/wp-content/uploads/doc_ wp/NINOS\%20MIGRANTES\%20baja.pdf

Convención de los Derechos del Niño. (20 de noviembre de 1989).

Corte Constitucional de Colombia. (28 de abril de 2011). Sentencia T 308, Recuperado de http://www.corteconstitucional.gov.co/ relatoria/2011/T-308-11.htm

Corte Constitucional, Bogotá, Colombia. (23 de septiembre de 2013). Sentencia T-660, 2013. Recuperado de http://www.corteconstitucional.gov.co/relatoria/2013/T-660-13.htm

Corte Constitucional, Bogotá, Colombia. (26 de abril de 2017). Sentencia T-250. Recuperado de http://www.corteconstitucional.gov. co/relatoria/2017/t-250-17.htm 
Corte Constitucional, Bogotá, Colombia. (29 de marzo de 2012). Sentencia T-260, 2012. Recuperado de http://www.corteconstitucional.gov.co/relatoria/2012/T-260-12.HTM

Diario El Espectador. (15/05/2018). Este viernes, 6 de abril, se inicia registro de migrantes venezolanos en Colombia. Recuperado de: https://www.elespectador.com/noticias/ politica/este-viernes-6-de-abril-se-iniciaregistro-de-migrantes-venezolanos-en-colombia-articulo-747446

Diario La República. (19/7/2018). Migración reportó que 870.093 venezolanos han cruzado la frontera para establecerse en el país. Recuperado de: https://www.larepublica. co/economia/migracion-reporto-que870093-han-cruzado-la-frontera-paraestablecerse-en-el-pais-2751267

Diario La Vanguardia. (18/12/2017). Hijos de venezolanos deberán tener visa de estudiante para acceder a colegios en Colombia. Recuperado de: http://www.vanguardia.com/ colombia/419029-hijos-de-venezolanos-deberan-tener-visa-de-estudiante-para-acceder-a-colegios-en-col

Diario Oficial de la República de Colombia. (2 de agosto 2016). Ley 1804. Bogotá - Colombia.

Diario Oficial de la República de Colombia. (20 de diciembre de 2011). Decreto 4807. Bogotá Colombia.

Diario Oficial de la República de Colombia. (25 de julio de 2018). Decreto 1288. Bogotá - Colombia.

Diario Oficial de la República de Colombia. (26 de mayo de 2015). Decreto Único Reglamentario del Sector Educación 1075. Bogotá - Colombia.

Diario Oficial de la República de Colombia. (27 de febrero de 2013). Ley Estatutaria 1618. Bogotá - Colombia.
Diario Oficial de la República de Colombia. (29 de mayo 2015). Decreto Reglamentario 1067. Bogotá - Colombia.

Diario Oficial de la República de Colombia. (8 de febrero de 1994). Ley 115, Ley General de Educación. Bogotá - Colombia.

Diario Oficial de la República de Colombia. (8 de noviembre de 2006). Ley 1098, Código de la Infancia y la Adolescencia. Bogotá - Colombia.

Edmonds, E. \& Shrestha, M. (2009). Children's Work and Independent Child Migration: a critical review. Recuperado de: https://www. unicef-irc.org/publications/586-childrenswork-and-independent-child-migration-acritical-review.html

Khoudour-Castéras, D. (2009). Efectos de la migración sobre el trabajo infantil en Colombia. Revista de Economía Institucional, 11, (20), 229-252. Recuperado de https://www. economiainstitucional.com/pdf/No20/ dkhoudour20.pdf

Mercosur. (2016). Derechos humanos de la niñez migrante. Migración y derechos humanos. Recuperado de: http://www.ippdh.mercosur.int/wp-content/uploads/2017/03/Derechos-Humanos-de-la-Ninez-Migrante.pdf

Ministerio de Educación Nacional. (16 de septiembre de 2015). Circular 45. Recuperado de https://www.mineducacion.gov.co/normatividad/1753/w3-article-353789.html

Ministerio de Educación y la Unidad Administrativa Especial Migración Colombia. (27 de abril de 2017). Circular Conjunta 1. Recuperado de http://www.cordoba.gov.co/ educacion/_contenido/noticias/2017/Circular_Conjunta_01_2017_MinEducacion_ Migracion_Colombia.pdf

Ministerio de Educación. (7 de febrero de 2016). Circular 7. Recuperado de https://www.mineducacion.gov.co/1759/articles-360397_ 
Dia2_06.pdf

Organización Internacional del Trabajo. (2013).

Niños, niñas y adolescentes en América

Central y México. Recuperado de: https:// www.ilo.org/ipec/Informationresources/ WCMS_IPEC_PUB_25755/lang--es/index. htm

Ortega, E. (2014). Los niños migrantes irregulares y sus derechos humanos en la práctica europea y americana: entre el control y la protección. Boletín Mexicano de Derecho Comparado, XLVIII, (142), 185-221. Recuperado de http://www.scielo.org.mx/pdf/ bmdc/v48n142/v48n142a6.pdf

Pacto Internacional de Derechos Económicos, Sociales y Culturales, Asamblea General. (16 de diciembre de 1966).

Pavez-Soto, I. (2016). Violencia sexual contra niñas migrantes en Chile: polivictimización, género y derechos. Revista Rumbos TS, XI, (14), 113-131. Recuperado de http://revistafacso.ucentral.cl/index.php/rumbos/article/view/404/368

Petit, J. M. (2003). Migraciones, vulnerabilidad y políticas públicas. Impacto sobre los niños, sus familias y sus derechos. Recuperado de https://repositorio.cepal.org/bitstream/ handle/11362/7178/1/S2003710_es.pdf

Protocolo de San Salvador. (17 de noviembre de 1988).

Ramirez, L. \& Ruiz, S. (2018). will Candelaria go to school? barriers to access education for venezuelan migrant children [mensaje en un blog]. Recuperado de: https://dejusticiablog.org/new-blog/2018/2/19/oaala69web77mzuvstlyr0i4va2v6h
Suárez-Cabrera, D. L. (2015). New immigrants, old racism: Participatory mapping and immigrant children in Chile. Revista Latinoamericana de Ciencias Sociales, Niñez y Juventud, 13, (2), 627-643. Recuperado de http:// www.scielo.org.co/scielo.php?script $=$ sci_ arttext\&pid=S1692-715X2015000200006

UNICEF. (2017). Más allá de las fronteras. Cómo lograr que los pactos mundiales sobre migración y refugiados protejan a los niños desarraigados. Nueva York - Estados Unidos: UNICEF.

Unidad Nacional para la Gestión del Riesgo de Desastres. (2018). Informe Final Registro Administrativo de Migrantes Venezolanos en Colombia. Recuperado de: http://portal.gestiondelriesgo.gov.co/ RAMV/Documentos\%20compartidos/ Presentacio\%CC\%81n\%20Final\%20Registro\%20de\%20Migrantes\%20Venezolanos\%20RAMV.PDF

Van de Glind, H. (2010a). Children on the Move: An ILO Perspective. Recuperado de: www.ilo.org/ipecinfo/product/download. do?type=document\&id=14418. (2010b). Migration and child labour - Exploring child migrant vulnerabilities and those of children left-behind. Recuperado de: www.ilo.org/ipecinfo/product/download. do? type $=$ document $\&$ id $=14313$

Yaqub, S. (2009). Child Migrants with and Without Parents: Census-Based Estimates of Scale and Characteristics in Argentina, Chile and South Africa. Innocenti Discussion Papers, IDP 2009 (02), 1-19. Recuperado de http:// www.unicef-irc.org/publications/549 